\title{
CONTRIBUTION OF CIGARETTE SMOKING TO RESPIRATORY DISEASE
}

\author{
BY \\ J. H. EDWARDS \\ From the Department of Social Medicine, University of Birmingham.
}

Evidence is accumulating of the association between cigarette smoking and carcinoma of the lung (Doll and Hill, 1952), respiratory tuberculosis (Lowe, 1956), and chronic bronchitis (Leese, 1956a). The purpose of this paper is to compare the intensity of these associations, to consider to what extent smoking may have influenced the incidence of these diseases, and to assess the relative effects of different degrees of smoking on life expectation.

\section{MATERIAL}

The analysis is based on published data. Doll and Hill's data refer to several series of consecutive patients with cancer of the lung, and patients with other diseases matched by sex and age; the total comprises 1,465 matched pairs $(1,357$ male and 108 female). A smoking history was taken from each pair, and there is overwhelming internal evidence that any biasses of the observations were trivial.

Lowe's data on tuberculosis refer to the smoking habits of 1,200 patients who were in sanatoria or attending chest clinics, and 979 "controls" taken from accident and general surgical cases; they are subdivided by sex and age (in decades). For this reason, and because they were more recent, Lowe's data on controls will be used throughout in estimating the probable influence of smoking on the liability of the population to cancer and tuberculosis of the lungs.

Leese's data form part of an inquiry into the histories and habits of 100 patients admitted to hospital because of an acute exacerbation of chronic bronchitis and 100 controls matched in respect of age and sex, selected from other ward patients.

\section{MethoD}

Relative liability to a disease, in relation to an attribute such as the number of cigarettes smoked, is proportional to the ratio of the number of patients to the number of individuals in the general population having that attribute. This is illustrated in Table I (prepared from data published by Lowe, 1956), which shows the approximate relative liability to tuberculosis in men over 30 years of age, according to the amount of tobacco smoked. Some of the numbers are, of course, rather small, and no account is taken of sampling errors, or of age trends in smoking habits and tuberculosis morbidity. In particular, because of the rarity of non-smoking, the "standard" is based on the ratio of comparatively small numbers (13 and 34). The exclusion from the controls of known sufferers from the disease considered will lead to a very slight exaggeration of the relative liabilities.

TABle I

APPROXIMATE RELATIVE LIABILITY TO TUBERCULOSIS NOTIFICATION ACCORDING TO THE AMOUNT SMOKED (MALES BETWEEN 30 AND 69 YEARS)

\begin{tabular}{|c|c|c|c|c|c|c|}
\hline $\begin{array}{l}\text { No. of } \\
\text { Cigarettes } \\
\text { Smoked } \\
\text { per Day }\end{array}$ & 0 & $1-9$ & $10-19$ & $20-29$ & $30-39$ & $\begin{array}{l}40 \text { and } \\
\text { over }\end{array}$ \\
\hline $\begin{array}{l}\text { Patients }(p) \\
\text { Controls }(q)\end{array}$ & $\begin{array}{l}13 \\
34\end{array}$ & $\begin{array}{l}48 \\
54\end{array}$ & $\begin{array}{l}198 \\
149\end{array}$ & $\begin{array}{l}153 \\
115\end{array}$ & $\begin{array}{l}59 \\
39\end{array}$ & $\begin{array}{l}49 \\
28\end{array}$ \\
\hline Ratio $\frac{p}{q}$ & 0.382 & 0.899 & $1 \cdot 33$ & $1 \cdot 33$ & $1 \cdot 51$ & $1 \cdot 75$ \\
\hline $\begin{array}{l}\text { Relative } \\
\text { Liability* }\end{array}$ & 1.00 & $2 \cdot 33$ & $3 \cdot 48$ & $3 \cdot 48$ & 3.95 & $4 \cdot 58$ \\
\hline
\end{tabular}

* Ratios divided by $0 \cdot 382[13 \div 34]$.

By somewhat more complicated methods (Appen$\operatorname{dix} A$ ), it is possible to minimize the errors due to sampling, and, incidentally, to reduce any bias due to the non-smoking minority being atypical in other ways (e.g. by including a higher proportion of non-drinkers or athletes), and these methods will be used throughout. When the relative liability of various classes of smoker has been estimated, the contribution of smoking to the total incidence of a disease, or to the resultant loss of life expectancy, 
may be made by summing the products of the proportion of individuals in each smoking class by its relative liability as shown in Table II.

TABLE II

RELATIVE LIABILITY OF MEN AGED 30 AND OVER TO TUBERCULOSIS

\begin{tabular}{c|c|c|c}
\hline $\begin{array}{c}\text { No. of } \\
\begin{array}{c}\text { Cigarettes } \\
\text { Smoked } \\
\text { per Day }\end{array}\end{array}$ & $\begin{array}{c}\text { Relative Liability } \\
\text { to Tuberculosis } \\
(a)\end{array}$ & $\begin{array}{c}\text { Distribution of } \\
\text { Male Controls } \\
(b)\end{array}$ & $(a) \times(b)$ \\
\hline 0 & $1 \cdot 00$ & $8 \cdot 1$ & $8 \cdot 1$ \\
$1-9$ & $1 \cdot 79$ & $12 \cdot 9$ & $23 \cdot 1$ \\
$10-19$ & $2 \cdot 47$ & $35 \cdot 6$ & 87.9 \\
$20-29$ & $2 \cdot 86$ & $27 \cdot 4$ & 78.4 \\
$30-39$ & $3 \cdot 19$ & $9 \cdot 3$ & $29 \cdot 7$ \\
40 and over & $3 \cdot 47$ & $6 \cdot 7$ & $23 \cdot 2$ \\
\hline & & $100 \cdot 0$ & $250 \cdot 4$ \\
\hline
\end{tabular}

This method of estimation assumes that the relative liability of smokers according to intensity of smoking is independent of age. In tuberculosis there is direct evidence that relative liabilities are fairly constant above the age of 30 . In cancer there is no direct evidence from Doll and Hill's age-

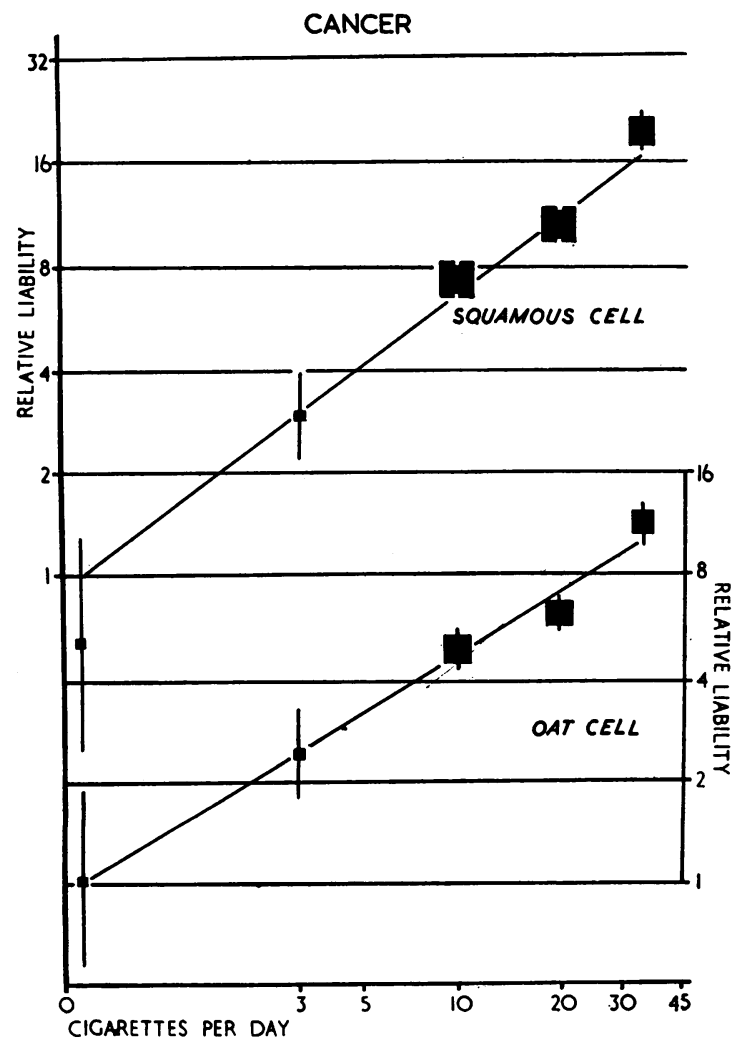

FIG. 1 (a).-Graphical presentation of data of Doll and Hill (1952) on squamous-cell and oat-cell carcinoma in men.

The area of the datum points is proportional to their weight. The vertical lines represent the standard error of their estimated position matched controls, but results which follow their use of "Estimated Annual Mortality Rates from Lung Cancer per 1,000 men aged 45-74 years" are very consistent. The remarkable manner in which various cohorts differ in liability to lung cancer by a fairly constant ratio at all ages (Cutler and Loveland, 1954) also suggests that the assumption is valid.

\section{RESULTS}

\section{CANCER OF THE LUNG}

The Intensity of the Response to Smoking.-Fig. $1(a)$ shows the relative liability to cancer of the lung of various classes of male smoker, each class being specified by the median number of cigarettes consumed daily. The lines represent Doll and Hill's data for squamous-cell and oat-cell carcinoma in men.

Table III (overleaf) shows estimates of $\beta$, a parameter (Appendix A) which defines the relative liability of various smokers to a given disease. It is so defined that a smoker of $t$ cigarettes daily has a relative liability of $(1+t)^{\beta}$ of developing a disease.

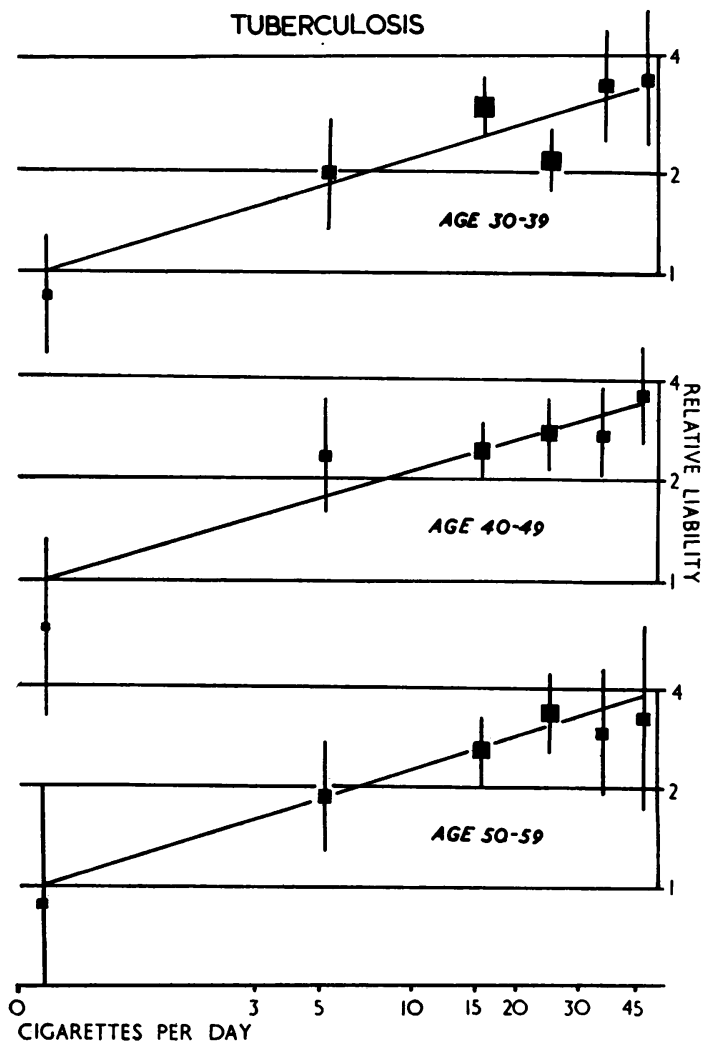

FIG. 1 (b).-Data of Lowe on tuberculosis in men of various ages. 
(When $\beta=0$ there is no association: increasing values imply an increasing intensity of association). Adenocarcinoma shows no significant association with smoking, and, in men, differs significantly in intensity of relationship from the other two cancers. Squamous-cell and oat-cell carcinomata appear to differ considerably in intensity of response, although in men this difference is not significant. In men, squamous-cell carcinoma is probably more closely related to smoking than oat-cell carcinoma; in women, the reverse is true.

TABLE III

ESTIMATES OF $\beta$

CANCER

\begin{tabular}{|c|c|c|}
\hline Type & Men & Women \\
\hline $\begin{array}{ll}\text { Oat-cell } & \ldots \\
\text { Squamous-cell } & \ldots \\
\text { Oat-cell and } & . \\
\text { Squamous-cell } & \\
\text { Adenocarcinoma } & \ldots\end{array}$ & $\begin{array}{r}+0.644 \pm 0.101 \\
+0.805 \pm 0.095 \\
{[+0.729 \pm 0.069]} \\
+0.124 \pm 0.265 t\end{array}$ & $\begin{array}{c}+0.565 \pm 0.199 \dagger \\
( \pm 0.104 \pm 0.212) \\
(+0.079 \pm 0.260)\end{array}$ \\
\hline \multicolumn{3}{|c|}{ TUBERCULOSIS } \\
\hline Age (yrs) & Men & Women \\
\hline $\begin{array}{l}20-24 \\
25-29 \\
30-39 \\
40-49 \\
50-59 \\
60-69\end{array}$ & $\begin{array}{l}-0.050 \pm 0.117 \dagger \\
+0.295 \pm 0.190 \dagger \\
+0.327 \pm 0.119 \\
+0.320 \pm 0.146 \\
+0.342 \pm 0.188 \\
+0.463 \pm 0.216\end{array}$ & $\begin{array}{r}+0.032 \pm 0.081 \\
+0.070 \pm 0.159 \dagger \\
+0.469 \pm 0.203 \dagger \\
(+0.248 \pm 0.243) \\
\text { Data inadequate }\end{array}$ \\
\hline $\begin{array}{l}30-49 \\
30-59 \\
\end{array}$ & $\begin{array}{l}{[+0.324 \pm 0.092]} \\
{[+0.328 \pm 0.083]}\end{array}$ & $\begin{array}{c}{[+0 \cdot 222 \pm 0 \cdot 125] \dagger} \\
\text { Data inadequate }\end{array}$ \\
\hline
\end{tabular}

† Residual heterogeneity above expectation, but not significantly so. Standard error corrected by Finney's heterogeneity factors. [ ] Weighted means. ( ) Indirect estimates; see Appendix B.

The relative liabilities to "cancer excluding adenocarcinoma". may be estimated, approximately, from the weighted mean of the estimates of $\beta$-for squamous-cell and oat-cell carcinoma. This simplification, if the difference is real, would involve confusion of arithmetic and geometric means, but would not lead to a bias exceeding 5 per cent. for the heavy smokers, or 2 per cent. for the overall effects of smoking. The line representing this mean, with its approximate 95 per cent. fiducial limits, is shown in Fig. 2 (opposite). In fact, the ratio of squamous-cell to oat-cell cancers in men is almost identical with the ratio of the numbers expected, if a population -in which the tumours were equally likely in non-smokers-had the smoking habits of the controls and the estimated relative liabilities referred to above. (If adenocarcinoma is not related to smoking, in the absence of smoking the estimated proportions of squamous-cell, oat-cell, and adenocarcinoma would be 36,37 , and 27 per cent. respectively).
From Lowe's recent data for the smoking habits of controls, the effect of smoking on such a population in relation to "cancer excluding adenocarcinoma" (Table IV) appears sufficient to account for about an eightfold increase ( 95 per cent. fiducial limits are 5.6 to 12.8 ). The inclusion of adenocarcinoma reduces this figure. Assuming, as the data suggest, that adenocarcinoma is not related to smoking, and, in the absence of smoking, would be responsible for about a quarter of cases of lung cancer, the increase in "lung cancer" in men associated with smoking would be about sevenfold (4.7 to $10 \cdot 5)$. That is to say, smoking would be causally related to about 84 per cent. (80 to 91 per cent.) of cases of lung cancer in men.

\section{TABLE IV}

RELATIVE LIABILITY OF MEN TO CARCINOMA OF THE LUNG (EXCLUDING ADENOCARCINOMA)

\begin{tabular}{c|c|c|c}
\hline $\begin{array}{c}\text { No. of } \\
\text { Cigarettes } \\
\text { Smoked } \\
\text { per Day }\end{array}$ & $\begin{array}{c}\text { Relative Liability } \\
\text { to Cancer of the } \\
\text { Lung (excluding } \\
\text { Adenocarcinoma) } \\
(a)\end{array}$ & $\begin{array}{c}\text { Distribution of } \\
\text { Male Controls } \\
(b)\end{array}$ & $(a) \times(b)$ \\
\hline 0 & $1 \cdot 00$ & $8 \cdot 1$ & $8 \cdot 1$ \\
$1-9$ & $3 \cdot 69$ & $12 \cdot 9$ & $47 \cdot 7$ \\
$10-19$ & $7 \cdot 56$ & $35 \cdot 6$ & $269 \cdot 0$ \\
$20-29$ & $10 \cdot 46$ & $27 \cdot 4$ & $286 \cdot 7$ \\
$30-39$ & $13 \cdot 37$ & $9 \cdot 3$ & $124 \cdot 4$ \\
$40+$ & $16 \cdot 32$ & $6 \cdot 7$ & $109 \cdot 3$ \\
\hline & & $100 \cdot 0$ & $845 \cdot 2$ \\
\hline
\end{tabular}

The distribution of men according to smoking habits is that of the control series published by Lowe (1956).

If the women are divided into smokers and nonsmokers, the relative liability of smokers, as a class, compared with non-smokers, to lung cancer (all types) may be assessed by Woolf's method (Woolf, 1955) with Haldane's continuity corrections (Haldane, 1956). This gives a relative liability of $2 \cdot 03(1 \cdot 16$ to $3 \cdot 56)$. Since $48 \cdot 6$ per cent. of women smoke (Lowe's data for women over 30), smoking has apparently led to an increase in incidence of only about 1.5 times $(1.08$ to $2 \cdot 24)$, and is related to about 34 per cent. of cancers ( $7 \cdot 3$ to 55 per cent.). If the liability to cancer of the lung were the same in men and women in the absence of smoking, smoking would result in a morbidity sex ratio of about $7 \div 1 \cdot 5$ or nearly 5 to 1 .

The extreme difference in the proportions of squamous-cell and oat-cell carcinoma in men and women recorded by Doll and Hill (475: 303 in men; $18: 38$ in women) implies some constitutional difference in response. Although the relative liability to oat-cell carcinoma, in relation to smoking, is comparable in men and women (Table III), there are large differences in estimated relative liability in men 


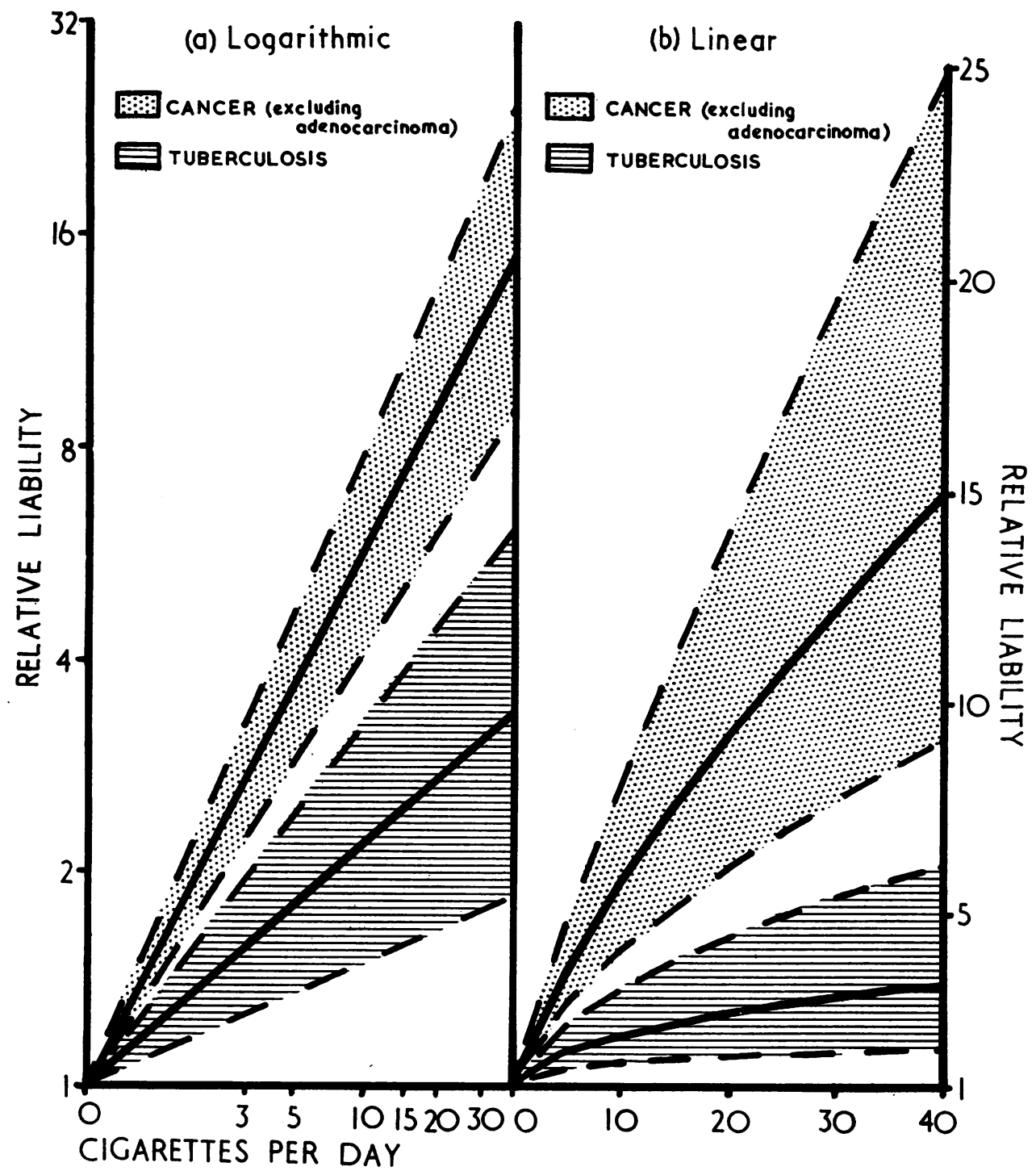

FIG. 2.-Estimates of relative liability of men smoking various numbers of cigarettes to cancer of the lung (excluding adenocarcinoma) and respiratory tuberculosis (men over 30 ).

and women to squamous-cell carcinoma, and these differences are unlikely to be due to the sampling errors of small numbers. The smallness of these numbers is itself a most important datum (Appendix B).

This relative immunity of women smokers to squamous-cell carcinoma appears to provide a sufficient explanation for most of the observed difference in mortality sex ratio (about 7 to 1). If women had the same liability to the various lung carcinomata, and smoking had the same effect on relative liability as in men, this would only lead to a morbidity sex ratio of about 2.5 to 1 (Fig. 3, overleaf, and Appendix A).

A sex difference in liability to cancer among persons of similar habits has many precedents. Gross sex differences in cancer rate are found in the brain, caecum, and rectum, while particularly large sex differences occur in the squamous carcinomata of the lips, larynx, and oesophagus. 


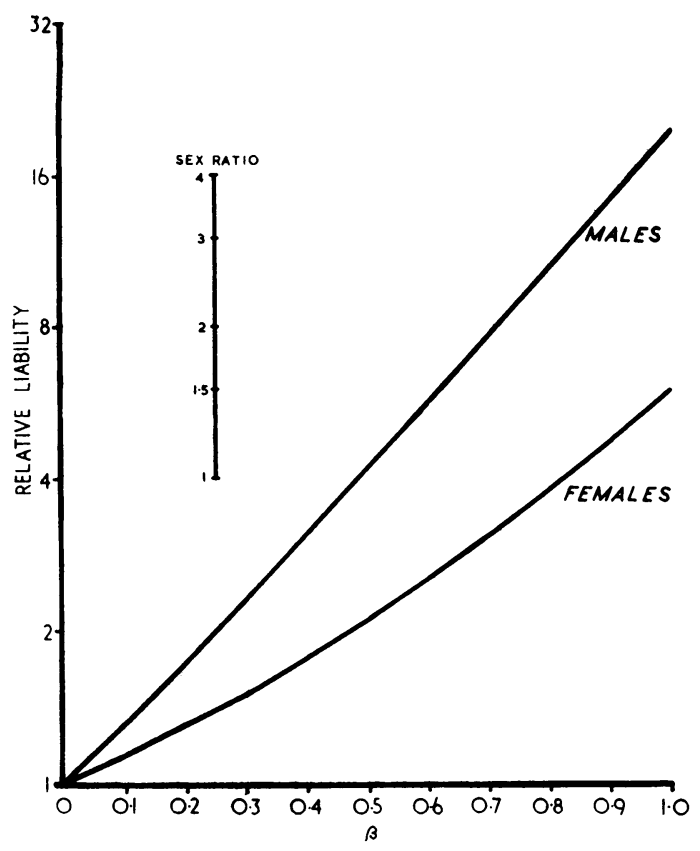

FIG. 3.-Relative liability of the present population (Lowe's control data for adults over 30), compared with a non-smoking population, to diseases having a response to smoking defined by $\beta$. The vertical distance between the lines shows the expected morbidity sex ratio.

Contribution of Smoking to Loss of Life Expectancy from Cancer of the Lung.-To apply to mortality data estimates based on morbidity it is necessary to assume that in diagnosed cases the proportion in which death is certified as due to a given cause is not negatively associated with the amount smoked (that is, roughly, it must be assumed that smoking, or having smoked, does not improve the prognosis); estimates of the contribution of smoking to loss of life will then be minimal estimates. The fact that more than one cause of death is related to smoking will also bias these estimates conservatively.

Table V (opposite) gives an estimate of the loss of life (man-years) in persons dying from three of the major respiratory diseases in England and Wales in 1954. It was obtained by multiplying the number of deaths in each age group by the expectation of life of the general population at the corresponding age. An estimate is also given of the mean loss of life expectancy at death from each disease.

In a previous section it was estimated that in cancer of the lung about 84 per cent. of cases in men and 34 per cent. in women were related to smoking. In 1954, smoker's cancer was apparently responsible for the deaths of about 12,000 men and 770 women, or, in terms of loss of expected life, about 170,000 man-years and 13,000 woman-years (Fig. 4). During this period about 67 thousand million cigarettes were smoked by men and 19 thousand million by women (Hulton Readership Survey, 1955).

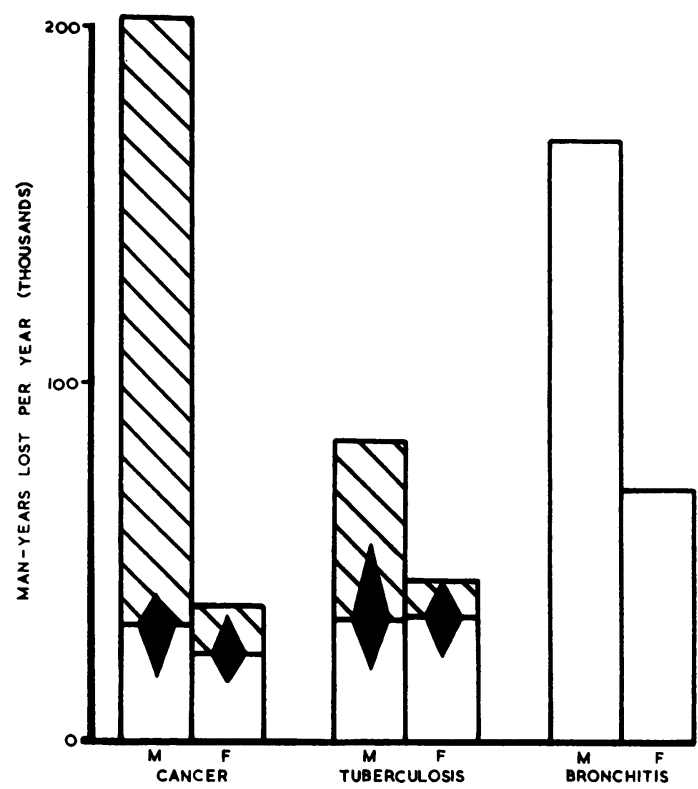

FIG. 4.-Loss of life (man-years per year) attributable to deaths, between the ages of 30 and 85 , from the common respiratory diseases. Shaded areas represent the estimated proportions related to smoking and the diamonds their 95 per cent. fiducial range. As the number of women over the age of 30 exceeds the range. As the number of women over the age of 30 exceeds the
number of men by about 15 per cent., because of their greater expectation of life which also averages about 15 per cent. greater, any disease with the same mortality rate in men and women would lead to a loss of life expectation for women about $30 \mathrm{per}$ cent. greater than that for men.

\section{Pulmonary Tuberculosis}

Intensity of the Response to Smoking.-Figs 1 and 2 show the relative liability of various classes of smoker to pulmonary tuberculosis for men whose ages lie within certain decades. Table III shows estimates of $\beta$, and its standard error, for various age groups of men and women. In some cases the data have been grouped because of small numbers.

For men over 30 years of age, there is a very consistent trend of increasing liability with increasing smoking, the trend being almost linear on a log$\log$ scale. The trend of relative liability is approximately that of the cube root of the number of cigarettes smoked daily (it is about doubled at 8 and trebled at 27 cigarettes a day). The fact that the moderate smoker is almost as seriously affected as the heavy smoker suggests that such explanations as associated drinking or impaired appetite are relatively unimportant. 
TABLE V

LOSS OF LIFE OF PERSONS AGED 30-85 FROM CERTAIN RESPIRATORY DISEASES, ENGLAND AND WALES, 1954

\begin{tabular}{|c|c|c|c|c|c|c|c|c|}
\hline \multirow{2}{*}{ Sex } & \multirow{2}{*}{ Age } & \multirow{2}{*}{$\begin{array}{c}\text { Expectation } \\
\text { of Life } \\
\text { (yrs) }\end{array}$} & \multicolumn{2}{|c|}{ Cancer } & \multicolumn{2}{|c|}{ Tuberculosis } & \multicolumn{2}{|c|}{ Bronchitis } \\
\hline & & & $\begin{array}{l}\text { No. of } \\
\text { Deaths }\end{array}$ & $\begin{array}{c}\text { Loss of } \\
\text { Man-years }\end{array}$ & $\begin{array}{l}\text { No. of } \\
\text { Deaths }\end{array}$ & $\begin{array}{c}\text { Loss of } \\
\text { Man-years }\end{array}$ & $\begin{array}{l}\text { No. of } \\
\text { Deaths }\end{array}$ & $\begin{array}{c}\text { Loss of } \\
\text { Man-years }\end{array}$ \\
\hline \multirow[t]{3}{*}{ Men } & $\begin{array}{l}30- \\
35- \\
40- \\
45- \\
50- \\
55- \\
60- \\
65- \\
70- \\
75- \\
80-85\end{array}$ & $\begin{array}{r}38 \cdot 0 \\
33 \cdot 3 \\
29 \cdot 8 \\
24 \cdot 4 \\
20 \cdot 3 \\
16 \cdot 6 \\
13 \cdot 3 \\
10 \cdot 4 \\
7 \cdot 9 \\
5 \cdot 9 \\
4 \cdot 3\end{array}$ & $\begin{array}{r}65 \\
129 \\
422 \\
982 \\
1,879 \\
2,425 \\
2,651 \\
2,502 \\
1,693 \\
853 \\
299\end{array}$ & $\begin{array}{r}2,470 \\
4,296 \\
12,576 \\
23,961 \\
38,144 \\
40,255 \\
35,258 \\
26,021 \\
13,382 \\
5,033 \\
1,286\end{array}$ & $\begin{array}{r}260 \\
249 \\
335 \\
476 \\
657 \\
620 \\
735 \\
616 \\
457 \\
193 \\
53\end{array}$ & $\begin{array}{r}9,880 \\
8,292 \\
9,983 \\
11,614 \\
13,337 \\
10,292 \\
9,776 \\
6,406 \\
3,610 \\
1,139 \\
228\end{array}$ & $\begin{array}{r}23 \\
54 \\
151 \\
387 \\
914 \\
1,497 \\
2,251 \\
2,935 \\
3,064 \\
2,687 \\
1,728\end{array}$ & $\begin{array}{r}874 \\
1,798 \\
4,500 \\
9,443 \\
18,554 \\
24,850 \\
29,938 \\
30,524 \\
24,206 \\
15,859 \\
7,430\end{array}$ \\
\hline & \multicolumn{2}{|c|}{ All Ages } & 13,900 & 202,682 & 4,651 & 84,557 & 15,691 & 167,976 \\
\hline & \multicolumn{2}{|c|}{ * Mean loss of life (yrs) } & \multicolumn{2}{|c|}{$14 \cdot 6$} & \multicolumn{2}{|c|}{$18 \cdot 2$} & \multicolumn{2}{|c|}{$10 \cdot 7$} \\
\hline \multirow[t]{3}{*}{ Women } & $\begin{array}{l}30- \\
35- \\
40- \\
45- \\
50- \\
55- \\
60- \\
65- \\
70- \\
75- \\
80-85\end{array}$ & $\begin{array}{r}42 \cdot 3 \\
37 \cdot 6 \\
33 \cdot 0 \\
28 \cdot 5 \\
24 \cdot 2 \\
20 \cdot 0 \\
16 \cdot 2 \\
12.6 \\
9.0 \\
7 \cdot 0 \\
5 \cdot 0\end{array}$ & $\begin{array}{r}28 \\
40 \\
88 \\
156 \\
233 \\
284 \\
335 \\
386 \\
352 \\
252 \\
106\end{array}$ & $\begin{array}{r}1,184 \\
1,504 \\
2,904 \\
4,532 \\
5,639 \\
5,680 \\
5,427 \\
4,864 \\
3,168 \\
1,764 \\
532\end{array}$ & $\begin{array}{l}250 \\
228 \\
228 \\
186 \\
149 \\
135 \\
147 \\
139 \\
128 \\
76 \\
39\end{array}$ & $\begin{array}{r}10,575 \\
8,573 \\
7,524 \\
5,301 \\
3,606 \\
2,700 \\
2,381 \\
1,751 \\
1,152 \\
532 \\
180\end{array}$ & $\begin{array}{r}18 \\
36 \\
40 \\
110 \\
197 \\
330 \\
539 \\
919 \\
1,288 \\
1,756 \\
1,584\end{array}$ & $\begin{array}{r}761 \\
1,354 \\
1,320 \\
3,135 \\
4,767 \\
6,600 \\
8,732 \\
11,579 \\
11,592 \\
12,292 \\
7,920\end{array}$ \\
\hline & \multicolumn{2}{|c|}{ All Ages } & 2,263 & 37,198 & 1,702 & 44,275 & 6,817 & 70,052 \\
\hline & \multicolumn{2}{|c|}{ * Mean loss of life (yrs) } & \multicolumn{2}{|c|}{$16 \cdot 4$} & \multicolumn{2}{|c|}{$26 \cdot 0$} & \multicolumn{2}{|c|}{$10 \cdot 3$} \\
\hline
\end{tabular}

* Mean loss of life expectancy at death ( $\left.\begin{array}{l}\text { Loss of man-years } \\ \text { Number of deaths }\end{array}\right)$

The data also suggest that smoking is relatively harmless in young adults, and that after middle age its harmfulness tends to increase. Fig. 2 shows the relative liabilities of men over 30 years of age smoking various numbers of cigarettes daily. The estimate for men aged 60-69 has been excluded because it is based on small numbers, but it would have led to a slightly steeper line and curve in Fig. 2 . The trivial association between tuberculosis and smoking in young adults appears to confirm Lowe's hypothesis that smoking may have little influence on the acquiring of infection, but may encourage the breakdown of old infections.

It may be added that, if smoking imposes relative liabilities to death from broken-down lesions similar to those it appears to impose on the breaking down of these lesions, and if smoking habits were uninfluenced by the therapeutic regimen, then the relative liability to death would be far greater than relative liability to notification. If smoking continued to be harmful after notification, the data may have been considerably biassed by the deaths of heavy smokers who could not be interviewed, a bias leading to underestimation of the intensity of association of smoking and morbidity.

From Lowe's data for the smoking habits of controls, the effect of smoking on such a population
(Table II) appears to be sufficient to account for an increase in the notification rate of men aged over 30 to about two and a half times ( 95 per cent. limits are 1.6 to $4 \cdot 1)$, implying that the proportion of such cases related to smoking is about 60 per cent. (37 to 76 per cent.). That is, at least one-third, and probably more than one-half, of notifications in men over 30 years of age appear to be related to smoking.

For women the estimates do not differ significantly from those for men, but suggest a less intense response. The estimate of $\beta$ for women aged 30-49 suggests a relative increase in incidence, due to smoking, of about $1.33(0.96$ to 1.87$)$, in which case smoking would be related to about 25 per cent. of all cases, or to about 50 per cent. of cases occurring in women smokers. This would lead to an influence of smoking on the morbidity sex ratio of about $2 \cdot 5 \div 1 \cdot 3$ or $1 \cdot 9$.

Contribution of Smoking to Loss of Life Expectancy from Pulmonary Tuberculosis.-Through rapid advances in the therapy of tuberculosis, the cost of smoking in terms of loss of life from this disease is likely to diminish rapidly, although the proportion of these deaths related to smoking will not necessarily change. There is no reason to expect much decrease in the number of men over 30 years of age 
with dormant lesions in the near future, and it seems likely that smoking will continue to promote an appreciable risk of tuberculosis until a generation of adults emerges in whom previous infection is rare.

Data from 1954 are presented in Table $\mathrm{V}$ and Fig. 4 for comparison with cancer and bronchitis. They refer only to the estimated loss of life of the smokers themselves, and not of those whose infection is consequent on smoking in others. As they are based on the assumption that the prognosis at the time of notification is unrelated to smoking, they are probably underestimates.

\section{Chronic Bronchitis}

Although most clinicians would probably regard heavy smoking as likely to encourage any tendency to bronchitis, there are few observations from which a quantitative estimate may be made. Leese (1956b), who found evidence that smoking was a predisposing cause in N.W. London, has kindly allowed me to use his data, which have been published in slightly less detail. In view of the chronic nature of the disease, total cigarette consumption seems the most suitable measure of dose, and, in men, the log liability exhibits a fairly linear response (Table VI and Fig. 5, opposite). The data suggest that smoking may contribute substantially to the incidence of chronic bronchitis. For example, the consumption of one-quarter of a million cigarettes ( 20 a day for 35 years) appears to result in a fourfold increase in the liability to enter hospital with an exacerbation of the disease.

Among women, smokers appear to be about five times as liable as non-smokers to enter hospital with the disorder (limits $1 \cdot 6$ to $15 \cdot 0$ ). This estimate is based on Haldane's modifications of Woolf's method. There were seventeen smokers and nine non-smokers among patients, and seven smokers and nineteen non-smokers among controls.

The intensity of association of smoking and bronchitis suggests that the great majority of bronchitic exacerbations in this series were related to smoking. It must be remembered, however, that the data were derived from an industrial area in which the air was heavily polluted, and provides no evidence about the effect of smoking in the absence of air pollution.

Although inferences based on morbidity data must be used with caution in relation to mortality, it seems likely that, at least in industrial areas, most deaths due to bronchitis are related to smoking, in that they would not be expected to occur in its absence. The contribution of bronchitis to loss of life in adults over age 30 is given (Table V, Fig. 4) but no attempt is made to estimate the contribution of smoking.

\section{Discussion}

Evidence has been advanced that, in three of the major respiratory causes of death in Britain, most cases in men over 30 years of age are related to smoking, in the sense that the estimated incidence, in the absence of smoking, would be less than half the present incidence. The fact that in each disease other influences are involved has led to some misunderstanding of the possible effect of smoking, and it may be worth while to consider briefly the interpretation of the evidence so far available.

It is evident that separate observations on the incidence of a disease in rural and urban areas, and in smokers and non-smokers, can provide only limited information about the relative importance of place of domicile and smoking habit. This is readily seen if the formal interpretation of data from such investigations is considered. Consider a population of A, B, C, and D persons, of whom a, $b$, $c$, and $d$ have cancer of the lung, when the letters imply the following attributes:

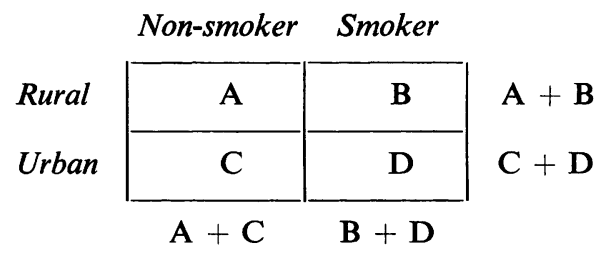

One investigator might show that $\frac{b+d}{B+D}$ exceeded $\frac{a+c}{A+C}$ and another that $\frac{c+d}{C+D}$ exceeded $\frac{a+b}{A+B}$. The former would have demonstrated that lung-cancer was associated with smoking; the latter that it was associated with place of domicile. These fractions, based on row and column totals, give no information about the proportion of individuals affected within each cell of the Table. And without this information it is of course impossible to arrive at an opinion about the extent to which the greater incidence of the disease in smokers than in nonsmokers is attributable $(a)$ to a risk associated with smoking, (b) to a risk associated with urban life and a greater proportion of urban dwellers among smokers than among non-smokers, or $(c)$ to a risk experienced only by smokers living in urban areas.

In the case of cancer of the lung, it seems quite certain that there is a risk associated with smoking which is independent of place of domicile. Perhaps the most direct evidence of this is the marked increase in the incidence of the disease in rural areas with increasing amounts smoked (Stocks and 
TABLE VI

SMOKING HISTORY OF MALE PATIENTS ADMITTED TO THE CENTRAL MIDDLESEX HOSPITAL WITH EXACERBATIONS OF CHRONIC BRONCHITIS AND OF AGE-MATCHED CONTROLS*

\begin{tabular}{|c|c|c|c|c|c|c|c|}
\hline \multirow{2}{*}{ Series } & \multicolumn{7}{|c|}{ Estimated Total Cigarette Consumption } \\
\hline & $\begin{array}{l}\text { Less than } \\
50,000\end{array}$ & $\begin{array}{c}50,000 \\
100,000\end{array}$ & $\begin{array}{r}100,000- \\
150,000\end{array}$ & $\begin{array}{c}150,000- \\
200,000\end{array}$ & $\begin{array}{c}200,000- \\
300,000\end{array}$ & $\begin{array}{c}\text { Over } \\
300,000\end{array}$ & Total \\
\hline Patients & 2 & 6 & 12 & 19 & 21 & 14 & 74 \\
\hline Controls & 7 & 17 & 18 & 11 & 16 & 5 & 74 \\
\hline
\end{tabular}

* Dr. W. L. B. Leese's data on the smoking histories in total cigarette consumption ( 1 oz. tobacco was regarded as equivalent to thirty cigarettes).

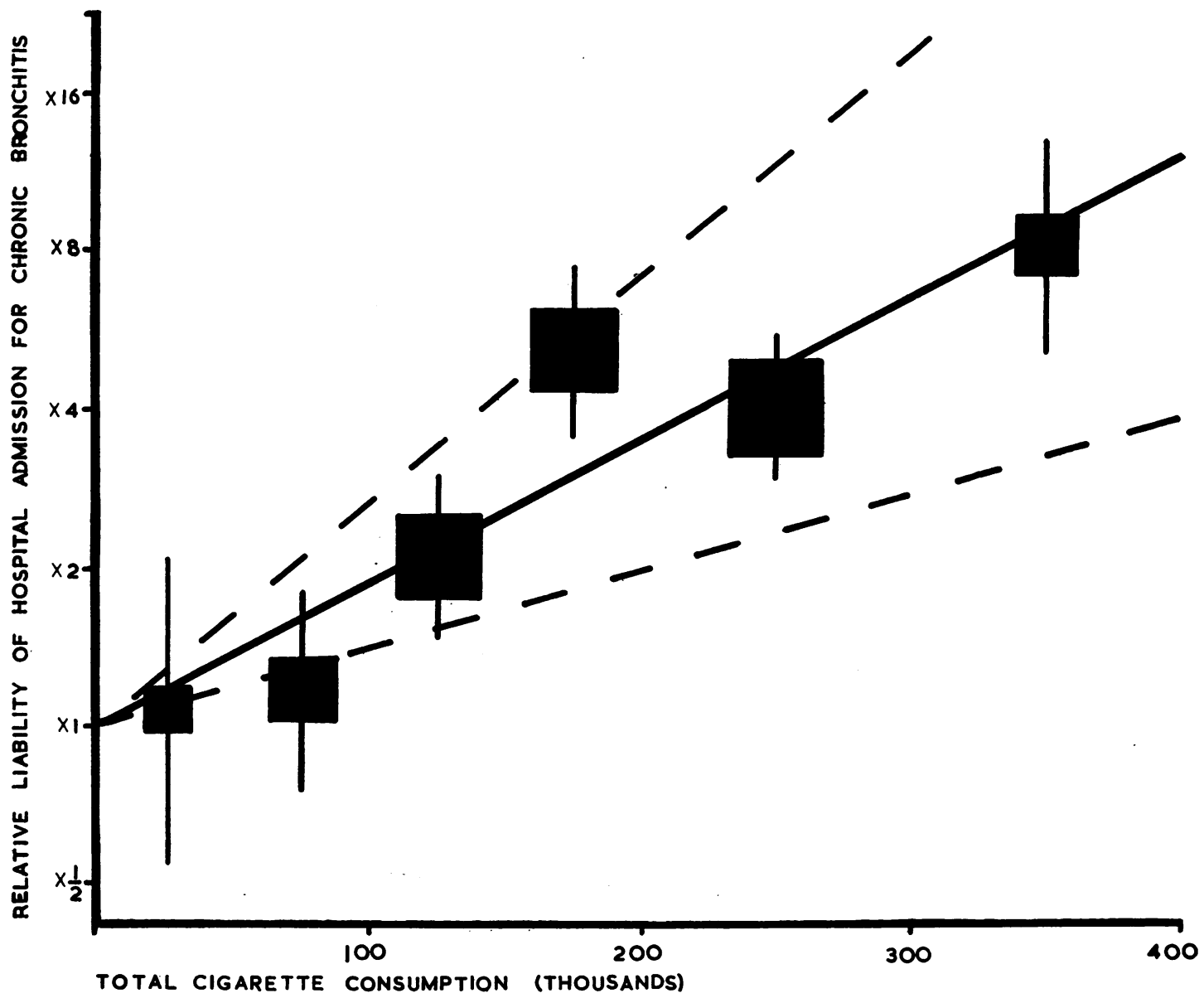

FIG. 5.-Relative liability of various smokers to exacerbations of chronic bronchitis. The area of the datum points is proportional to their weight. The vertical lines represent the standard error of their estimated position. The central line is the line of best fit, and the outer lines represent a 95 per cent. fiducial range in relative liabilities.

Campbell, 1955) and the secular rise in rural Norway (Kreyberg, 1956). But the same conclusion is also supported by the observations of Doll and Hill (1952) and others. For there is no doubt that the liability to cancer of the lung is very much greater in smokers as compared with non-smokers than in urban as compared with rural dwellers. In these circumstances the association between the disease and smoking could not be attributable wholly to an association between the disease and place of domicile, even if all smokers lived in urban areas and all non-smokers lived in the country. 
It is also probable that there is a risk of cancer of the lung associated with urban life, which is independent of smoking, since Stocks and Campbell (1955) showed that the incidence of the disease is higher in non-smokers living in towns than in nonsmokers living in the country. Kreyberg (1956) has suggested that this is an unlikely possibility, in view of the marked increase in the incidence of cancer of the lung in Oslo where the degree of air pollution was relatively low. But the incidence of the disease in Oslo is still very much below the incidence in England and Wales, and it can scarcely be concluded that it would not have been much higher in the presence of marked air-pollution (if we accept this as the most probable explanation of the risk associated with urban life). Moreover the data provided by Kreyberg indicate that, although considerably lower than that in an English town, the degree of air-pollution in Oslo was by no means negligible. It is not doubted, of course, that the sharp rise in the incidence of cancer of the lung in Oslo is attributable almost wholly to smoking; all that is in question is whether this evidence permits us to dismiss the possibility of an independent association with urban life.

The third possibility which we must consider is that part of the observed risk of cancer of the lung is experienced only by smokers living in towns, that is that there is some interaction or synergism between the two influences, such that the elimination of either would be sufficient to remove the effect. There is so far no direct evidence on this point. But the fact that the incidence of cancer of the lung is very much higher in England than in New Zealand, although the average cigarette consumption per head of the population is higher in New Zealand (Eastcott, 1956), suggests that the risk to which a smoker is exposed in an urban area is considerably greater than would be expected if the risks associated with smoking and urban life were whollyindependent. For it has been shown above that in England at least 80 per cent. of the incidence of cancer of the lung in men is associated with smoking. The fact that the incidence is about $\mathbf{5 0}$ per cent. lower in New Zealand, where rather more tobacco is smoked, strongly suggests that a substantial part of the risk associated with smoking in England is determined by the coincident influences of smoking and urban life. If this interpretation is correct, the elimination either of smoking or of the effects of urban life could lead to a major reduction in mortality, and it is unfortunate that the association of one should have been used to discredit the value of prophylaxis in the other.

In chronic bronchitis the extreme social, geo- graphical and occupational variations in incidence appear to have led to a belief that smoking cannot be a major factor, since smoking shows only slight social, geographical, and occupational variations. This reasoning is invalid. Smoking may be a necessary factor in most cases, in the sense that in its absence they would not have developed, even if some other factor or factors, such as atmospheric pollution, dust, overcrowding, exposure, or undernourishment, were essential to this development in most cases. The evidence, now widely accepted, that most cases of chronic bronchitis are related to exposure to combustion products, or to particulate matter from industrial processes, is most readily compatible with the evidence advanced here on Leese's data, if there is interaction between these effects.

\section{The Threshold of Excess In SMoking}

The degree to which the liability to cancer and tuberculosis of the lung is dependent on the amount smoked is of extreme practical importance: the "common sense" view of many smokers, clinicians, and tobacco companies is that moderation is fairly innocuous, and that it is only the heavy smoker who is exposing himself to an appreciable risk. There is good evidence that this type of response is true of alcohol, but the analogy is false. In drinking the pleasure and the damage are due to the same substance, and irreversible damage rarely follows except after repeated exposures to concentrations in excess of those usually demanded for pleasure. In tobacco smoke, on the other hand, the constituents responsible for pleasure are probably different from those responsible for damage, and there is no a priori reason why amounts of tobacco usually regarded as insufficient to confer pleasure should be inadequate to cause disease. Nor is there any reason to suppose that by some coincidence the factors conferring pleasure and disease should be so proportioned that moderation in indulgence should give freedom from illness.

If each cigarette were equally harmful, whatever the amount smoked, then the relation between relative liability and dose would be represented by straight lines. The fact that they are not (Fig. 2b) and that their convexities are upward, implies that the damage done per cigarette per day in terms of the increased liability to cancer and tuberculosis, is at a maximum in the light smoker, and steadily decreases with increasing amounts smoked. The limited evidence available for bronchitis (Fig. 5) is suggestive of a disproportionate risk to the heavy smoker, the damage per cigarette appearing to increase with the amount smoked. 
These considerations suggest that the incidence of cancer, and particularly of tuberculosis, would be lower if half of all smokers stopped smoking than if all smokers halved their smoking. For any given rate of national consumption, the damage within any age group would be at a maximum if distribution were even. If sales were maintained at a fixed level or rate of increase by advertising, the discouragement of heavy smoking would increase the incidence of these diseases. Their incidence might well be greater in a society which discourages heavy smoking but maintains its revenue by advertising, than in one which sanctions unlimited smoking but prohibits advertisement.

\section{SUMMARY}

The morbidity response to cigarettes, in the form of oat-cell and squamous-cell carcinoma and respiratory tuberculosis, can be closely approximated by a linear regression of log-liability against logdose, a type of response common in other forms of bio-assay.

In cancer of the lung, smoking appears to be related to over three-quarters of cases in men, and to about one-third in women. The different forms of cancer show a different relative increase in predisposition, and the differences are not consistent in men and women. The combination of these differences with the sex-differences in smoking habit appears almost sufficient to explain the sex-ratio in mortality rate.

In tuberculosis, smoking appears to be related to over one-half of cases in men over 30 years of age and to about one-quarter in women, and, as in the case of cancer, there is evidence that smoking increases the liability to tuberculosis in men more than in women smoking the same amount. This difference in response, combined with difference in habit, would lead to a sex ratio in morbidity of almost 2 to 1 .

In relation to chronic bronchitis the data are less extensive, but they suggest that most cases would not occur in the absence of smoking.

The relationship of degree of smoking to liability to both cancer and tuberculosis is such that the harm done per cigarette per day decreases with increasing amounts smoked. There is no threshold. Warnings directed exclusively against heavy smoking may have paradoxical consequences.

The curtailment of life due to the common respiratory diseases in men in England and Wales, is over 1,200 man-years daily. Probably well over onehalf of this loss of life is related to smoking.

\section{REFERENCES}

Cutler, S. J., and Loveland, D. B. (1954). J. nat. Cancer Inst., 15, 201 Doll, R., and Hill, A. Bradford (1952). Brit. med. J., 2, 1271.

Eastcott, D. F. (1956). Lancet, 1, 37-39.

Finney, D. J. (1952). "Statistical Method in Biological Assay". Griffin, London.

Haldane, J. B. S. (1956). Ann. hum. Genet., 20, 309.

Kreyberg, L. (1956). British Journal of Preventive and Social Medicine, $10,145$.

Leese, W. L. B. (1956a). Lancet, 2, 762.

(1956b). Personal communication.

Lowe, C. R. (1956). Brit. med. J., 2, 1081.

Stocks, P., and Campbell, J. M. (1955). Ibid., $2,923$.

"The Hulton Readership Survey, 1955", produced annually by the British Market Research Bureau. Ninth year of publication. Hulton Press, London.

Woolf, B. (1955). Ann. hum. Genet., 19, 251.

\section{APPENDIX A}

The inexactness and bias imposed by sampling may be estimated and allowed for by considering the natural logarithm of a ratio, rather than the ratio itself, and weighting this datum by the inverse of its sampling variance. These data may then be handled by simple regression analysis, and, if necessary, the significance of any trend may be tested by partitioning variance. A discussion of allied problems has been presented by Finney (1952, and elsewhere). Haldane (1956) has shown that an almost least biassed efficient estimator of this natural logarithm of a proportion from a sample consisting of two numbers, say $p$ and $q$, is given by:

$$
\log _{e} \frac{p+\frac{1}{2}}{q+\frac{1}{2}}
$$

with sampling variance:

$$
\frac{1}{p+1}+\frac{1}{q+1}
$$

and that its sampling distribution is almost normal,

This transformation is similar to the well-known logit transformation. Continuity corrections have 
been used throughout: although not explicitly recommended by Haldane for $n \times 2$ Tables where $n$ exceeds 2, any bias they may impose by overcorrection is conservative, leading to under-estimation of $\beta$ (as is obvious if the influence of indefinitely increasing the number of class frequencies is considered). The corrections also overcome the intuitively unreasonable shortcoming of simple logits in which the upper fiducial limit of $\frac{0}{q}$ always exceeds $\frac{p}{q}$, where $q$ and $p$ are any integers.

Fig. 1 shows a simple visual presentation of some data from Doll and Hill, and from Lowe. It may be noted that, if a horizontal line is moved up and down through a set of datum points, and the sum of the squares of the ratio of the vertical distance between the line and the point, to the standard error of that point, is estimated, then the minimum value will approximate to the simple $\chi^{2}$ estimation for an $n \times 2$ Table, one degree of freedom being lost in defining the position. If both the position and the slope are adjusted to minimize this sum of squares, as by simple regression, an efficient estimate of trend is achieved.

The use of $\chi^{2}$ has the shortcomings that it is insensitive to the order of these points, and that, for any given intensity of association, its value is proportional to the size of the sample. This leads to the paradox that, if statistical significance is regarded as of importance, the seriousness of the implications of any set of data judged significant varies inversely with its size.

The trend in Fig. 1 is so marked and consistent that computations are almost superfluous; in Table III the slope of the regression line is given as estimates of the parameter $\beta$.

This parameter is so defined that, if $t$ cigarettes are smoked daily, the relative liability of various smokers is $(1+t)^{\beta}$. Where smokers are graded by classes, the median* is taken as $t$. The regression analysis is then of the form of

$$
\log _{e} \frac{P_{t}}{Q_{t}}=\alpha+\beta \log _{e}(1+t),
$$

where $P_{t}$ and $Q_{t}$ represent the number of patients and controls smoking $t$ cigarettes daily, and $\log _{e} \frac{p_{t}+\frac{1}{2}}{q_{t}+\frac{1}{2}}$ are estimates, based on samples $p_{t}$ and $q_{t}$, of $\log _{e} \frac{P_{t}}{Q_{t}}$, these estimates being weighted.

For the non-smoker $(t=0),(1+t)^{\beta}$ will always be unity.

\footnotetext{
* When the median was not unique, the median nearer the mean was taken. 45 was taken as the median for $40+, 35$ for $25+$, and for women 25 for $20+$.
}

The parameter $\beta$ has the simple features that positive values imply a positive association, zero values no association, and negative values a negative association (in this case, a protective influence of smoking). Values between 0 and 1 (in the absence of appreciable residual heterogeneity) imply that the damage per cigarette decreases with increasing amounts smoked. The estimator is independent of the incidence of the underlying disease: the fact that many smokers cannot develop tuberculosis, due to not having been infected, in no way impairs its validity.

Table VII shows values of $(1+t)^{\beta}$ for various values of $t$ and $\beta$. For example, where $\beta=0 \cdot 6$, a smoker of twenty cigarettes daily has a relative liability, compared with a non-smoker, of $6 \cdot 21$; and, compared with a smoker of ten cigarettes daily, of $6 \cdot 21 \div 4 \cdot 21$ or $1 \cdot 5$.

TABLE VII (APPENDIX A)

VALUES OF $(1+t)^{\beta}$ FOR VARIOUS VALUES OF $t$ AND $\beta$

\begin{tabular}{|c|c|c|c|c|c|c|c|}
\hline \multirow{2}{*}{$\beta$} & \multicolumn{7}{|c|}{$t$ (cigarettes per day) } \\
\hline & 0 & 5 & 10 & 15 & 20 & 30 & 40 \\
\hline $\begin{array}{l}0 \\
0.1 \\
0.2 \\
0.3 \\
0.4 \\
0.5 \\
0.6 \\
0.7 \\
0.8 \\
0.9 \\
1 \cdot 0\end{array}$ & $\begin{array}{l}1.00 \\
1.00 \\
1.00 \\
1.00 \\
1.00 \\
1.00 \\
1.00 \\
1.00 \\
1.00 \\
1.00 \\
1.00\end{array}$ & $\begin{array}{l}1 \cdot 00 \\
1.20 \\
1.43 \\
1.71 \\
2.05 \\
2.45 \\
2.93 \\
3.51 \\
4.19 \\
5.01 \\
6.00\end{array}$ & $\begin{array}{r}1.00 \\
1.27 \\
1.61 \\
2.05 \\
2.61 \\
3.31 \\
4.21 \\
5.36 \\
6.81 \\
8.65 \\
11.00\end{array}$ & $\begin{array}{r}1.00 \\
1.32 \\
1.74 \\
2.30 \\
3.03 \\
4.00 \\
5.27 \\
6.96 \\
9.18 \\
12.02 \\
16.00\end{array}$ & $\begin{array}{r}1 \cdot 00 \\
1 \cdot 36 \\
1 \cdot 84 \\
2 \cdot 49 \\
3 \cdot 38 \\
4 \cdot 58 \\
6 \cdot 21 \\
8 \cdot 42 \\
11 \cdot 42 \\
15 \cdot 49 \\
21 \cdot 00\end{array}$ & $\begin{array}{r}1.00 \\
1.41 \\
1.99 \\
2.80 \\
3.95 \\
5.56 \\
7.85 \\
11.07 \\
15.60 \\
21.99 \\
31.00\end{array}$ & $\begin{array}{r}1 \cdot 00 \\
1.45 \\
2.10 \\
3.05 \\
4.42 \\
6.40 \\
9.29 \\
13.45 \\
19.51 \\
28.28 \\
41.00\end{array}$ \\
\hline
\end{tabular}

Fig. 3 shows the relative liability of populations of men and women over 30 years of age with the smoking habits of Lowe's controls, compared with a non-smoking population. The gap between the lines is proportional to the logarithm of the sex ratio which would follow from any equal response, defined by $\beta$, in the two sexes.

These population relative liabilities are simply the sum of the products of the proportion of the population in each smoking class and the relative liability of that class. The proportion of cases related to smoking can be estimated from this figure.

If $q_{0}, q_{1}, \ldots q_{n}$ are the proportions of the population in smoking classes $0,1, \ldots n$, and $l_{0}, l_{1}, \ldots l_{n}$ are their relative liabilities to disease $\left(l_{0}\right.$ being defined as unity), then the population liability will be $q_{0} l_{0}+q_{1} l_{1},+\ldots q_{n} l_{n}$ and the proportion of cases causally related to smoking (in the sense that they would not be expected to have this disease if they had not smoked) will be:

$$
\frac{\left(q_{0} l_{0}+q_{1} l_{1}+\ldots q_{n} l_{n}\right)-\left(q_{0}+q_{1}+\ldots q_{n}\right)}{\left(q_{0} l_{0}+q_{1} l_{1}+\ldots q_{n} l_{n}\right) .}
$$


The relative proportions of various types of cancer in the absence of smoking may be estimated directly. The effect of dilution of data by a type of cancer not related to smoking is easily estimated. Where $r$ is the increase in liability due to smoking of one type of cancer, and $s$ is the estimated proportion of a second type of cancer in the absence of smoking, then the overall increase is

$$
\frac{r+s}{1+s}
$$

Lowe's data on controls have been assumed to be exactly representative of the country as a whole. This simplifying assumption is unlikely to have led to any appreciable bias, apart from slight overestimation of the precision of estimates.

Woolf 's method of analysis has frequently been used. In a $2 \times 2$ Table, interaction of the characters considered may most simply be expressed by the ratio of the cross products. If, for example, patients with some disease were divided into $p_{0}$ non-smokers and $p_{t}$ smokers, and the controls into $q_{0}$ non-smokers and $q_{t}$ smokers, then the most meaningful expression of interaction would be:

$$
\frac{p_{t} / p_{0}}{q_{t} / q_{0}}, \text { or } \frac{p_{t} q_{0}}{q_{t} p_{0}},
$$

which would define the relative liability of smokers compared to non-smokers to the disease.

Woolf (1955) pointed out that the natural logarithm of this product is an efficient estimator and has a sampling variance of:

$$
\frac{1}{p_{0}}+\frac{1}{p_{t}}+\frac{1}{q_{0}}+\frac{1}{q_{t}}
$$

Haldane (1956) showed that an almost least biassed estimator of the logarithm of this cross ratio, and its sampling variance, is provided by:

and

$$
\log _{e} \frac{\left(p_{t}+\frac{1}{2}\right)\left(q_{0}+\frac{1}{2}\right)}{\left(q_{t}+\frac{1}{2}\right)\left(p_{0}+\frac{1}{2}\right)}
$$

$$
\frac{1}{p_{0}+1}+\frac{1}{p_{t}+1}+\frac{1}{q_{0}+1}+\frac{1}{q_{t}+1} \text {. }
$$

\section{APPENDIX B}

The following appears to be an approximate, yet fairly rigorous, solution to the problem of whether men and women could reasonably be considered to be exposed to the same relative liabilities, in relation to smoking, of acquiring squamous-cell carcinoma.

There were eleven non-smokers out of eighteen women with squamous-cell cancer, and 59 nonsmokers out of 108 controls. The estimate of the natural logarithm of the relative liability of "smokers" to squamous-cell cancer is therefore: $\log _{e}\left[\frac{7 \cdot 5 \times 59 \cdot 5}{49 \cdot 5 \times 11 \cdot 5}\right] \pm \sqrt{\left[\frac{1}{8}+\frac{1}{12}+\frac{1}{50}+\frac{1}{60}\right]}$, or

$$
-0.244 \pm 0.495 \text {. }
$$

The relationship between this log-liability of smokers as a class is approximately linearly related to values of $\beta$. For women whose smoking habits were those of Lowe's control series, the relationship is approximately:

$$
\beta=0.428 \times \log \text {-liability of smokers. }
$$

For women with squamous-cell carcinoma, this indirect estimate of $\beta$ is $-0 \cdot 104 \pm 0 \cdot 212$. For men, the direct estimate is $+0.805 \pm 0.095$. As the difference is almost four times its standard error, there seems no reasonable chance that it is due to a sampling effect in the presence of an identical dose-response. 